Check for updates

Cite this: RSC Adv., 2017, 7, 32065

Received 27th October 2016 Accepted 30th May 2017

DOI: $10.1039 / c 6 r a 25946 d$

rsc.li/rsc-advances

\section{Microencapsulation of $\alpha$-tocopherol with zein and $\beta$-cyclodextrin using spray drying for colour stability and shelf-life improvement of fruit beverages $\dagger$}

\author{
C. Saldanha do Carmo, (DD ${ }^{\text {ab }}$ C. Maia, ${ }^{\text {ab }}$ Joana Poejo, (DD ab I. Lychko, ${ }^{\text {ab }}$ P. Gamito, ${ }^{\text {ab }}$ \\ I. Nogueira, ${ }^{C}$ M. R. Bronze, (DD abd Ana Teresa Serra (D) *ab \\ and Catarina M. M. Duarte (D) *ab
}

$\alpha$-Tocopherol (TOC) has become an important food additive due to its antioxidant effect and capacity to increase shelf-life of products. However, it is a hydrophobically active compound, which compromises its applicability in soft drinks and fruit beverages. The aim of this study was to develop sustained release forms of $\alpha$-tocopherol using zein and cyclodextrin as carriers to be further applied in fruit beverage products for improved shelf-life. For this purpose, the encapsulation of $\alpha$-tocopherol into zein protein was first optimized using a spray-drying technology. Different process conditions, namely temperature $\left(110-180{ }^{\circ} \mathrm{C}\right)$ and solids concentration $\left(0.01-0.04 \mathrm{~g} \mathrm{~mL}^{-1}\right)$, were tested aiming at maximizing the encapsulation of $\alpha$-tocopherol and antioxidant capacity using response surface methodology (RSM) following a Face Centred Design (FCD). Results showed that lower inlet gas temperature and lower solids concentration enable the production of $\alpha$-tocopherol:zein forms with a higher antioxidant activity (oxygen radical absorbance capacity $>90 \mu \mathrm{mol}$ Trolox equivalent antioxidant capacity per g), and the highest encapsulation efficiency (42.05\%) was obtained using $0.02 \mathrm{~g} \mathrm{~mL}^{-1}$ of solids concentration. $\beta$ Cyclodextrin was further added to the best system to increase the solubility capacity of $\alpha$-tocopherol in fruit juice beverages. Despite the lower antioxidant activity $(46.2 \mu \mathrm{mol}$ Trolox equivalent antioxidant capacity per g), $\alpha$-tocopherol:zein:cyclodextrin forms reduced colour losses when compared to the normal juice, and this effect was probably related to the suppression of anthocyanin degradation due to the formation of inclusion complexes with $\beta$-cyclodextrin. Importantly, none of these forms induced cytotoxicity in the Caco2 cell model, confirming the safety of these systems.

\section{Introduction}

In recent times, an increasing interest has been observed in employing food biopolymers to fabricate delivery systems of bioactive compounds due to their non-toxicity, biocompatibility and biodegradability. ${ }^{1}$ Apart from the focus of researchers on the delivery of functional ingredients in foods that bring health benefits, the food industry is also interested in bioactive substances that are also able to improve processing efficiency

aiBET, Instituto de Biologia Experimental e Tecnológica, Apartado 12, 2780-901 Oeiras, Portugal. E-mail: tserra@ibet.pt; cduarte@itqb.unl.pt

${ }^{b}$ Instituto de Tecnologia Química e Biológica António Xavier, Universidade Nova de Lisboa (ITQB NOVA), 2780-157 Oeiras, Portugal

${ }^{c}$ CEFEMA, Instituto Superior Técnico, Universidade de Lisboa, Av. Rovisco Pais, 1049001 Lisboa, Portugal

diMED, Faculdade de Farmácia da Universidade de Lisboa (FFUL), Av. Prof. Gama Pinto, 1649-019 Lisboa, Portugal

$\dagger$ Electronic supplementary information (ESI) available. See DOI: 10.1039/c6ra25946d and maintain quality of food products during processing, transportation and storage. In this field, antioxidants are widely used to enhance the oxidative stability and extend the shelf-life of products. ${ }^{2}$

Tocopherols comprise a class of bioactive compounds that includes various methylated phenols. Tocopherols are extremely valuable compounds because of their bioactivity as vitamins and capacity as anti-oxidizing agent. ${ }^{3}$ Vitamin $\mathrm{E}$ includes both tocopherols and tocotrienols that occur in groups of four $(\alpha, \beta, \gamma, \delta)$ lipophilic antioxidants synthesized by photosynthetic organisms. $\alpha$-Tocopherol is the isomer with highest vitamin E activity, and it has become an important additive of numerous food products due to its biological properties, ${ }^{4-7}$ including antioxidant effect, ${ }^{8}$ which can promote the shelf-life of products. However, vitamin $\mathrm{E}$ is hydrophobically active, which makes it difficult to be directly dispersed into an aqueous phase, ${ }^{9}$ compromising its applicability in soft drinks and fruit beverages. In addition, it is labile to heat and oxygen; 
for example, $\alpha$-tocopherol is irreversibly converted to quinone via epoxide formation when exposed to oxygen and heat. ${ }^{\mathbf{1 0}}$

As important as the active principle, is the way to deliver/ incorporate it in specific food systems. Moreover, its protection from degradation could be significantly improved by using the convenient carriers. Micro- and nano-encapsulated forms of antioxidants are choices of easy application that can overcome this issue, helping to increase the shelf-life of fruits and other products of high demand like fruit beverages, thereby reducing product losses. Moreover, edible coatings containing antioxidants can be used to decrease browning of fruit-based products. ${ }^{11}$

Zein is the major storage protein from corn, which is considered as a prolamine due to its characteristic hydrophobicity. It has been studied as a versatile food biopolymer to fabricate nanoparticles for encapsulating a large variety of bioactive compounds. ${ }^{12,13}$ In contrast to hydrophilic animal proteins, zein, a hydrophobic plant protein, enables the production of sustained-release particulate systems, which might not require any further chemical treatment to harden them, thus preventing use of toxic chemical crosslinkers. ${ }^{2}$ Moreover, the use of plant-protein-based delivery systems may offer novel functional foods to consumers particularly for vegans. Zein is also known for its high thermal resistance and great oxygen barrier properties, ${ }^{\mathbf{1 4}}$ making it suitable to encapsulate food antioxidants. Processing temperature is an important factor for various proteins because they denature at high temperatures, causing irreversible structural changes. Zein has a very stable structure, requiring high concentration of denaturants, $\mathrm{pH}$, or elevated temperature to produce structure changes. ${ }^{15}$ In recent years, zein has been applied in the development of delivery systems to encapsulate several hydrophobic active ingredients using different methodologies, such as curcumin by evaporation, followed by freeze-drying, ${ }^{16}$ vitamin D3 by freeze-drying, ${ }^{17}$ lutein by solution enhanced dispersion by supercritical fluids (SEDS), ${ }^{18}$ and quercetin by complexation followed by freeze-drying. ${ }^{19}$ Zein was also used to prepare TOC nanoparticles coated with chitosan, demonstrating to be a promising delivery system for hydrophobic nutrients due to the improvement of TOC slow release and better protection against gastrointestinal conditions. ${ }^{20}$ This study confirmed the occurrence of electrostatic interactions between $\alpha$-tocopherol and zein.

Recently, several studies have been conducted to investigate the impact of having stabilizers, namely arabic gum, sodium caseinate and chitosan, to facilitate zein dispersion in water and provide protection of active principles against gastrointestinal conditions and enhance its releasing property. ${ }^{\mathbf{9 , 1 2 , 2 0}}$ In this field, cyclodextrins are very attractive due to their ability to form complexes with the target compounds and protect them against oxidation and heat-induced degradation ${ }^{21}$ and improve the solubility of zein in aqueous food products. ${ }^{22}$

In this study, a novel micro-scale delivery system of $\alpha$ tocopherol using zein and cyclodextrins was developed to improve the shelf-life and colour stability of fruit beverages. Response surface methodology (RSM) was used to model the encapsulation of the antioxidant into zein protein using spray- drying technology. The influence of temperature and solids concentration on the encapsulation efficiency and antioxidant activity was evaluated. $\beta$-Cyclodextrin was further added to the best formulation aiming at improving the solubility of zein: $\alpha$ tocopherol forms in aqueous systems and the shelf-life of fruit juices.

\section{Experimental}

\section{Materials}

Corn zein (NF F4400C non-GMO/food grade) was supplied by Flo Chemical Corporation (Ashburnham, MA, USA); $\alpha$-tocopherol $\geq 95.5 \%$ was purchase from Sigma-Aldrich Chemical Co. Ltd. (St. Louis, MO, USA); ethanol absolute 99.9\% was purchase from Scharlau (Sentmenat, Barcelona, Spain); $\beta$-cyclodextrin (Cavamax® W7 Food) was supplied by Wacker Chemie AG (München, Germany).

Chemicals used for antioxidant activity assays (ORAC) included $2^{\prime}, 2^{\prime}$-azobis(2-amidinopropane)dihydrochloride (AAPH), 6-hydroxy-2,5,7,8-tetramethylchroman-2-carboxylic acid (Trolox), and disodium fluorescein (FL) and they were obtained from TCI Europe (Antwerp, Belgium).

Reagents used for phosphate buffered solution (PBS) preparation included sodium phosphate monobasic monohydrate $\left(\mathrm{NaH}_{2} \mathrm{PO}_{4} \cdot \mathrm{H}_{2} \mathrm{O}\right)$ from Sigma-Aldrich (St. Quentin Fallavier, France) and sodium phosphate dibasic heptahydrate $\left(\mathrm{Na}_{2}-\right.$ $\mathrm{HPO}_{4} \cdot 6 \mathrm{H}_{2} \mathrm{O}$ ) from Riedel-de-Haën (Seelze, Germany).

Reagents used for cytotoxicity: all cell culture media and supplements, namely, RPMI 1640 medium, 10\% of fetal bovine serum (FBS), 1\% penicillin-streptomycin (PS) and trypsin/EDTA (0.25 trypsin-EDTA $(1 \times)$ ), were obtained from Invitrogen (Invitrogen Corporation, Paisley, UK). Phosphate buffered saline (PBS) powder was obtained from Sigma-Aldrich (St. Louis, MO, USA), and CellTiter 96® AQueous One Solution Cell Proliferation Assay was obtained from Promega (Wisconsin, USA).

\section{Methods used for the encapsulation of $\alpha$-tocopherol}

Preparation of zein: $\alpha$-tocopherol complex solutions (TOC:Z). The TOC: $\mathrm{Z}$ solutions were prepared by adding $\mathrm{Z}$ and TOC to $75 \%(\mathrm{v} / \mathrm{v})$ ethanol solution and mixing it using magnetic stirring (200 rpm, $30 \mathrm{~min}$, room temperature), according to the target solids concentration (Table 1 ) and a ratio of TOC : $\mathrm{Z}$ of $1: 6$. This ratio was selected and fixed after preliminary trials concerning homogeneity of dispersion by visual observation. After their preparation, they were pumped into the spray dryer.

Preparation of zein : $\alpha$-tocopherol $(1: 6)$ solution with addition of $\beta$-cyclodextrin in $40 \%$ EtOH. After the best

Table 1 Actual values of the variables for the coded values

\begin{tabular}{llll}
\hline & Levels & & \\
\cline { 2 - 4 } & -1 & 0 & +1 \\
\hline Variable, factors, unit & 110 & 150 & 180 \\
Temperature, $T\left({ }^{\circ} \mathrm{C}\right)$ & 0.01 & 0.02 & 0.04
\end{tabular}


formulation was obtained, $\beta$-cyclodextrin was added as a protecting agent during spray-drying process that simultaneously enhances the solubility of zein in aqueous systems. Two solutions were prepared separately, both using $40 \%$ ethanol, which is an intermediate solubility between zein and $\beta$-cyclodextrin. ${ }^{23}$ To prepare the first solution, $2.5 \mathrm{~g}$ of zein was solubilized in 200 $\mathrm{mL}$ of ethanol at $50{ }^{\circ} \mathrm{C}$. For the preparation of the second solution, $1.85 \mathrm{~g}$ of $\beta$-cyclodextrin was solubilized in $100 \mathrm{~mL}$ of ethanol, and then $0.5 \mathrm{~g}$ of $\alpha$-tocopherol was added (inclusion complex). The two solutions were mixed together after cooling (room temperature) of the first solution and homogenised, leading to a final volume of $300 \mathrm{~mL}$ that was pumped into the spray dryer.

Spray-drying process. TOC:Z and TOC:CD:Z solutions were spray-dried using a Büchi Mini Spray Dryer B-290 (Flawil, Switzerland) equipped with a $0.7 \mathrm{~mm}$ diameter nozzle. The feed mixture was fed at 7-9 $\mathrm{mL} \mathrm{min}^{-1}$, and feed temperature was about $23{ }^{\circ} \mathrm{C}$ (room temperature). The pressure of the gas (nitrogen) for the flow of spray was adjusted to $2.0 \mathrm{bar}$, and the aspiration flow was set to $35 \mathrm{~m}^{3} \mathrm{~h}^{-1}$. The inlet temperature was set according to each experimental design condition (Table 2) with an air flow rate of $357 \mathrm{~L} \mathrm{~h}^{-1}$. TOC:CD:Z solution was dried under the optimum process conditions. The spray-dried powders were collected in the cyclone and put in a hermetically sealed container and stored at $4{ }^{\circ} \mathrm{C}$ until further analysis.

Experimental design (process optimization). Response Surface Methodology (RSM) was used to model the encapsulation of $\alpha$-tocopherol into the zein carrier. RSM consists of a set of mathematical and statistical methods developed for modelling phenomena and finding combinations of a number of experimental factors (variables) that will lead to optimum responses. With RSM, several variables are tested simultaneously with a minimum number of trials, using special experimental designs that enable one to find interactions between the variables that cannot be identified with classical approaches. ${ }^{24}$ The encapsulation of $\alpha$-tocopherol through spraydrying process was carried out following a Central Composite Face Centred Design (CCFCD), as a function of two factors: temperature and solids concentration. A total of 10 experiments were performed. The temperature varied from $110{ }^{\circ} \mathrm{C}(-1)$ to
$180{ }^{\circ} \mathrm{C}(+1)$ and the solids concentration from $0.01 \mathrm{~g} \mathrm{~mL}^{-1}(-1)$ to $0.04 \mathrm{~g} \mathrm{~mL}^{-1}(+1)$, according to the experimental design (Table 2 ). The repetitions of the centre points (C) are used to determine the experimental error, which is assumed to be constant along the experimental domains.

\section{Characterization of the encapsulated forms}

Scanning electron microscopy (SEM). Morphology of encapsulated forms was observed by scanning electron microscopy (FEG-SEM) (JEOL, JSM-5310 model, Japan) at 20/25 $\mathrm{kV}$, and samples were coated with approximately $300 \AA$ of gold in argon atmosphere.

Attenuated total reflectance-Fourier transform infrared spectroscopy (ATR-FTIR). A Thermo Scientific FTIR spectrometer (San Jose, USA), Class 1 Laser Product Nicolet 6100, was used. The equipment included an accessory with a diamond ATR crystal. The crystal provided an angle of incidence of 45 . The software used for FTIR data collection was Omnic version 7.3 (Thermo Electron Corporation). Before analysis, the instrument was purged with nitrogen for $15 \mathrm{~min}$. As a reference, the background spectrum of air was collected before the acquisition of the sample spectrum. After each sample, the crystal was rinsed with acetone and then dried with a soft tissue. To record the spectra, the solid sample was poured on the ATR crystal. Spectra were recorded with a resolution of $4 \mathrm{~cm}^{-1}$, and 32 scans were averaged for each spectrum (scan 4000-550 $\mathrm{cm}^{-1}$ ).

Yield of collected encapsulated forms. The yield of collected TOC:Z and TOC:CD:Z microparticles produced by spray drying was determined by the ratio (\%) of the amount of the obtained particles in the sample collector and the amount of mass initially pumped into the equipment.

Dynamic light scattering (DLS). A dynamic light scattering (DLS) analyzer (Zetasizer Nano ZS, Malvern Instruments Ltd., $\mathrm{UK}$ ) was used to measure the mean diameter ( $Z$-average, volume distribution) of the spray-dried particles. The measurements were conducted according to the method described by Regier et al., 2012. ${ }^{25}$ Briefly, particles were first suspended in $2 \mathrm{~mL}$ of Milli-Q water and then diluted further with phosphate buffered saline, pH 7.4 (PBS), due to the inability of particles to initially

Table 2 The Central Composite Face-Centred Design (CCFCD) for the two independent variables

\begin{tabular}{llll}
\hline & Variables & & \\
\cline { 2 - 3 } $\begin{array}{lll}\text { Experiment } \\
\text { number }\end{array}$ & $\begin{array}{l}\text { Temperature, } \\
T\left({ }^{\circ} \mathrm{C}\right)\end{array}$ & $\begin{array}{l}\text { Solids concentration } \\
\left([\text { solids }]\left(\mathrm{g} \mathrm{mL}^{-1}\right)\right)\end{array}$ & Responses \\
\hline 1 & 110 & 0.01 & \\
2 & 110 & 0.04 & Yield of collected particles $(\%)$ \\
3 & 180 & 0.01 & Encapsulation load (mg TOC per mg particles) \\
4 & 180 & 0.04 & Encapsulation efficiency $(\%)$ \\
5 & 110 & 0.02 & \\
6 & 180 & 0.02 & \\
7 & 150 & 0.01 & \\
8 & 150 & 0.04 & \\
$9(\mathrm{C})$ & 150 & 0.02 & \\
$10(\mathrm{C})$ & 150 & 0.02 &
\end{tabular}


be completely suspended in PBS. All measurements were carried out at $25{ }^{\circ} \mathrm{C}$, and the results were reported as averages of three readings.

Quantification of $\alpha$-tocopherol by LC-MS (liquid chromatography-mass spectrometry). The LC-MS analyses were performed on a Waters Alliance HPLC system (Waters ${ }^{\circledR}, 2695$ separation module, Ireland) comprising a quaternary pump, an on-line solvent degasser, autosampler and a column oven. The particles formed during the design of experiments (TOC:Z) and the particles containing $\beta$-cyclodextrin (TOC:CD:Z) were analysed to quantify $\alpha$-TOC present in each sample. The column associated with the equipment was the SunFire C18, $100 \times 2.1$ $\mathrm{mm}, 5 \mu \mathrm{m}$ (Waters ${ }^{\circledR}$, Ireland) at $35{ }^{\circ} \mathrm{C}$, using an injection volume of $10 \mu \mathrm{L}$. The mobile phase consisted of an ethanol solution containing $0.5 \% \mathrm{v} / \mathrm{v}$ of formic acid in Milli-Q water (eluent A) and acetonitrile (eluent B). A flow rate of $0.30 \mathrm{~mL}$ $\min ^{-1}$ was used, and the gradient conditions applied consisted of a linear increase from $2 \%$ eluent A to $98 \%$ eluent B in 15 minutes. MS/MS experiments were performed on Micromass ${ }^{\circledR}$ Quattro Micro triple quadrupole (Waters ${ }^{\circledR}$, Ireland) with an electrospray in positive ion mode $\left(\mathrm{ESI}^{+}\right)$, with ion source at $120^{\circ} \mathrm{C}$, capillary voltage of $3.0 \mathrm{kV}$ and source voltage of $30 \mathrm{~V}$. The compound was ionized, and the spectra of the column eluate were recorded in the range of $m / z 60-1000$. Analytical conditions were optimized to maximize the precursor ion signal $\left([\mathrm{M}+\mathrm{H}]^{+}\right)$. For the MS/MS experiments, different collision energies (eV) were applied to determine characteristic fragments. All analyses were performed in multiple reaction monitoring (MRM) mode in order to achieve a higher selectivity and sensitivity (MRM1 [431 > 111]; MRM2 [431 > 165]). MassLynx software (version 4.1) was used for data acquisition and processing.

Oxygen radical absorbance capacity (ORAC). The ORAC assay was carried out by the method of Huang et al., 2002, modified for the FLx800 microplate fluorescence reader (Bio-Tek Instruments, Winooski, VT, USA) ${ }^{26}$ as described by Feliciano et al., $2009 .{ }^{27}$ This assay measured the ability of the antioxidant species in the sample to inhibit the oxidation of disodium fluorescein (FL) catalysed by peroxyl radicals generated from AAPH. The final ORAC values were represented as Effective Concentration (EC) as described by Bolling et al., 2012. ${ }^{28}$ The results were presented as $\mu \mathrm{mol}$ of the Trolox equivalent antioxidant capacity (TEAC) per $g$ of particles and were expressed as a mean of two replicates.

Experimental design/statistical analysis. The results of the FCD, concerning the yield of collected particles (YCP), encapsulation load (EL), encapsulation efficiency (EE) and oxygen radical absorbance capacity (ORAC), were analysed using the software Statistica ${ }^{\mathrm{TM}}$, version 10, from Statsoft (Tulsa, USA). Both linear and quadratic effects of each factor under study as well as their interactions were calculated. Their significance was evaluated by analysis of variance. A surface, described by a second-order polynomial equation, was fitted to each set of experimental data points. First- and second-order coefficients of the polynomial equations were generated by regression analysis. The fit of the models was evaluated by the determination coefficients $\left(R^{2}\right)$ and adjusted $R^{2}\left(R_{\mathrm{adj}}{ }^{2}\right) \cdot{ }^{29,30}$

\section{Cytotoxicity evaluation in Caco2 cells}

Cell culture. Human $\mathrm{Caco} 2$ cell line was obtained from Deutsche Sammlung von Mikroorganismen und Zellkulturen (DSMZ, Germany). This cell line was cultured in RPMI 1640 medium supplemented with $10 \%$ of heat-inactivated fetal bovine serum (FBS) and $2 \mathrm{mM}$ of glutamine. Cells were maintained at $37{ }^{\circ} \mathrm{C}$ with $5 \% \mathrm{CO}_{2}$ in a humidified incubator and routinely grown as a monolayer in $75 \mathrm{~cm}^{2}$ culture flasks. The cell culture medium and supplements were purchased from Invitrogen (Gibco, Invitrogen Corporation, Paisley, UK).

Cytotoxicity assay. Cytotoxicity assays were performed using confluent and non-differentiated Caco 2 cells. This cell model shares some characteristics with crypt enterocytes, and thus it has been considered as an accepted intestinal model widely implemented to assess the effect of chemical and food compounds on the intestinal function. ${ }^{31-33}$ The assay was performed as previously described by A. T. Serra et al. (2010), with some modifications. ${ }^{34}$ Briefly, cells were seeded at a density of 2 $\times 10^{4}$ cells per well in 96-well plates, and the medium was changed every 2 days. After 8 days of culture, cells were incubated with different freshly prepared dilutions from homogeneous stock suspensions (10 $\mathrm{mg} \mathrm{mL}^{-1}$ ) of each particulate system, as described by several authors. ${ }^{35,36}$ The range of concentrations tested for both samples was $0.04-10 \mathrm{mg} \mathrm{mL}{ }^{-1}$. Control wells were performed by incubating the cells with the culture medium. After 24 and 48 hours of incubation, the medium was removed, and $100 \mu \mathrm{L}$ of the colorimetric reagent MTT $\left(0.5 \mathrm{mg} \mathrm{mL}^{-1}\right)$ was added to each well and left for $4 \mathrm{~h}$. MTT is reduced to a purple formazan product by mitochondrial reductase enzyme active cell viability in viable cells, and therefore, the amount of formazan product is proportional to the number of viable cells. ${ }^{37}$ Reaction was stopped with DMSO (150 $\mu \mathrm{L}$ per well), and formazan was quantified by measurement of the absorbance at $570 \mathrm{~nm}$. Results were calculated in terms of percentage of cellular viability relative to the control (\%). Experiments were performed in triplicate using two independent assays.

Shelf-life stability tests. The effect of TOC:Z and TOC:CD:Z particles on the shelf-life stability of strawberry juice with soluble solids content of $8^{\circ}$ Brix (g sucrose per $100 \mathrm{~g}$ product) was assessed by measuring their colour properties. Fresh strawberries were immersed in vinegar (40\%) for 30 minutes to reduce microbial activity and crushed using a domestic juice extractor. Juice was immediately filtered to remove seeds and pulp and frozen at $-25{ }^{\circ} \mathrm{C}$. Frozen juice samples were used within one week of juice preparation. Briefly, $1 \mathrm{~g}(\% \mathrm{w} / \mathrm{w})$ of TOC:Z forms and $0.59 \mathrm{~g}(\% \mathrm{w} / \mathrm{w})$ of TOC:CD:Z forms were added to $100 \mathrm{~mL}$ of strawberry juice. Non-encapsulated TOC was also tested by adding $0.18 \mathrm{~g}(\% \mathrm{w} / \mathrm{w})$ of TOC to the juice. The amount of TOC added to the juice was based on the amount of tocopherol per serving usually encountered in fortified drinks $\left(12.67 \%\right.$ of the daily recommended value $\left.{ }^{28}\right)$. The accelerated aging process was carried out by incubation of the juices for 10 days at $37{ }^{\circ} \mathrm{C}$, which equals to about 9 months of storage. The colour of the strawberry juice was assessed by CIElab method using a Minolta colorimeter CR-200 (Osaka, Japan) described 
using 3 attributes or specific qualities of visual sensation: tonality, luminosity and chromatism. CIELab colour or space system is based on a sequential or continuous Cartesian representation of 3 orthogonal axes: $L^{*}, a^{*}$ and $b^{*}$. Coordinate $L^{*}$ represents clarity ( $L^{*}=0$ black and $L^{*}=100$ colourless), $a^{*}$ green/red colour component ( $a^{*}>0$ red, $a^{*}<0$ green) and $b^{*}$ blue/yellow colour component ( $b^{*}>0$ yellow, $b^{*}<0$ blue). $C^{*}$ is the chroma or colour purity, and $h^{\circ}$ refers to the hue angle of tone and indicates the sample's colour $\left(0^{\circ}\right.$ or $360^{\circ}=\mathrm{red}, 90^{\circ}=$ yellow, $180^{\circ}=$ green, and $270^{\circ}=$ blue). $C^{*}$ was determined according to the expression $C^{*}=\left[\left(a^{*}\right)+\left(b^{*}\right)^{2}\right]^{1 / 2}$ and $h^{\circ}$ according to the expression $h^{\circ}=\arctan \left(b^{*} / a^{*}\right) .^{38}$ The colour parameters were expressed as a mean of triplicates. Euclidean distances between two points in the threedimensional space define by $L^{*}, a^{*}$, and $b^{*}$ were used for calculating colour differences $\left(\Delta E_{\mathrm{ab}}^{*}\right.$ of CIElab): $\Delta E_{\mathrm{ab}}^{*}=\left[\left(\Delta L^{*}\right)^{2}+\left(\Delta a^{*}\right)^{2}+\left(\Delta b^{*}\right)^{2}\right]^{1 / 2}$. The results were expressed in accordance with the CIElab system with reference to illuminant D65. ${ }^{38}$ Statistical analysis was carried out using GraphPad Prism 5 software. Data are mean \pm SD from at least duplicate data. One-way ANOVA analysis with Turkey's post multiple comparison test was performed to assess differences between samples. Statistical significance was found for $p<0.05$.

\section{Results and discussion}

\section{Modelling of TOC encapsulation into zein protein through spray-drying technology}

Aiming at producing zein-encapsulated forms of $\alpha$-tocopherol to be further incorporated in beverages the spray-drying process was modelled and optimized according to the CCFC design previously described (Table 2 ). The obtained results, i.e. $\alpha$ tocopherol load, encapsulation efficiency (EE), yield of collected particles (YCP) and ORAC values, are shown in Table 3.

These results were used to estimate both linear and quadratic effects of variables and also their linear interactions (see ESI $\dagger$ ). For the YCP, EL and EE, a lack of fit of the polynomial models exhibited by low values of $R^{2}$ and $R_{\text {adj }}^{2}$ was observed.

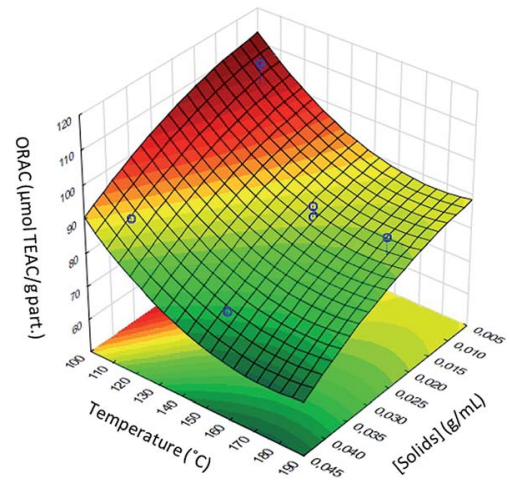

Fig. 1 Response surface fitted to the ORAC as a function of temperature and solid concentration.

The response surface (Fig. 1) fitted to ORAC values can be described by a second-order polynomial model as a function of temperature $(T)$ and solids concentration ([solids]) (Table 4). In these response surface models, the significant effects with $p<$ 0.05 and those having confidence range smaller than the value of the effect, or smaller than the standard deviation (data not shown), were included in the model equations of this surface. It is better to accept a factor with values higher than 0.05 rather than to take the chance of missing an important factor. ${ }^{30}$

The good values for both $R^{2}$ and $R_{\text {adj }}{ }^{2}$ of these models (Table 4) suggest a close agreement between the experimental data and the theoretical values predicted by the model. About $92 \%$ of the observed results concerning the ORAC are explained by the present model. However, only the identification of the region corresponding to the best response could be achieved. The best response was achieved at a temperature of $110{ }^{\circ} \mathrm{C}$ and solids concentration of $0.01 \mathrm{~g} \mathrm{~mL}^{-1}$.

The analysis of the data showed that there was a significant negative linear effect of [solids] and $T$ on the ORAC values, indicating that as the [solids] and $T$ increased (independently), the ORAC value decreased, meaning that when the encapsulation process was conducted at higher temperatures or higher [solids], the antioxidant activity of the systems decreased. This

Table 3 Summary of experimental results

\begin{tabular}{|c|c|c|c|c|c|c|c|c|}
\hline Samples & DOE \# & $T\left({ }^{\circ} \mathrm{C}\right)$ & $\begin{array}{l}\text { [Solids] } \\
\left(\mathrm{g} \mathrm{mL}^{-1}\right)\end{array}$ & YCP (\%) & $\begin{array}{l}\text { Load } \\
\text { (mg TOC per } \\
\text { mg particles) }\end{array}$ & $\mathrm{EE}(\%)$ & $\begin{array}{l}\text { ORAC } \\
\text { ( } \mu \text { mol TEAC per } \\
\text { g particles })\end{array}$ & $\begin{array}{l}Z \text { Z-Average } \\
\text { (nm) }\end{array}$ \\
\hline SD zein & - & - & - & - & - & - & $59.7 \pm 1.7$ & - \\
\hline \multirow[t]{8}{*}{ Experiment number } & 1 & 110 & 0.01 & 61.67 & $0.063 \pm 0.0035$ & 31.40 & $106.2 \pm 7.0$ & $1523.3 \pm 377.2$ \\
\hline & 2 & 110 & 0.04 & 72.79 & $0.070 \pm 0.0028$ & 34.80 & $87.5 \pm 2.2$ & $2359.7 \pm 819.2$ \\
\hline & 5 & 110 & 0.02 & 57.72 & $0.084 \pm 0.0002$ & 42.05 & $96.4 \pm 0.4$ & $5199.5 \pm 236.9$ \\
\hline & 6 & 180 & 0.02 & 43.57 & $0.075 \pm 0.0015$ & 37.36 & $86.9 \pm 0.7$ & $5384.0 \pm 149.9$ \\
\hline & 7 & 150 & 0.01 & 60.90 & $0.075 \pm 0.0009$ & 37.71 & $88.2 \pm 2.4$ & $4583.5 \pm 265.2$ \\
\hline & 8 & 150 & 0.04 & 66.49 & $0.073 \pm 0.0042$ & 36.34 & $75.8 \pm 1.8$ & $8534.0 \pm 240.4$ \\
\hline & $9(\mathrm{C})$ & 150 & 0.02 & 47.93 & $0.073 \pm 0.0007$ & 36.62 & $86.0 \pm 2.5$ & $3772.5 \pm 724.8$ \\
\hline & $10(\mathrm{C})$ & 150 & 0.02 & 76.50 & $0.069 \pm 0.0003$ & 34.51 & $87.9 \pm 0.7$ & $2127.0 \pm 260.2$ \\
\hline
\end{tabular}


Table 4 Model equation for the response surfaces fitted to the values of ORAC as a function of temperature ( $T$ ) and solids concentration ([solids]) and respective $R^{2}$ and $R^{2}$ adj

\begin{tabular}{lr}
\hline Polynomial model equation & $R^{2}$ \\
\hline ORAC $=226.595-56.451\left[\right.$ solids] $-992.932[\text { solids] }]^{2}-1.587 T+0.005 T^{2}$ & 0.92
\end{tabular}

can be due to the degradation of $\alpha$-tocopherol and zein pigments under higher temperatures once these compounds are thermosensitive. ${ }^{39,40}$ The antioxidant activities obtained were between 64.9 and 106.2 $\mu$ mol TEAC per $g$ particles. The repeatability (coefficient of variation) of the encapsulation process through spray drying was around $4.2 \%$, taking into account two samples of the design (centre points).

As shown in Table 3, YCP (mass of particles collected/mass of product introduced in the pressure vessel) was between 43.57 and $77.67 \%$, being higher at higher temperatures $\left(180{ }^{\circ} \mathrm{C}\right)$ and higher solids concentration $\left(0.04 \mathrm{~g} \mathrm{~mL}^{-1}\right)$. Quispe-Condori et al., 2011, have reported similar findings that can be possibly explained by the fact that a larger amount of zein together with higher temperatures (less stickiness) might have allowed the formation of thicker microparticle walls. ${ }^{\mathbf{4 1}}$ In this study, flax oil was microencapsulated with zein using spray and freeze drying, and similar process yields (64.22-78.97\%) were obtained. ${ }^{41}$ However, it is important to highlight that the highest temperature used in this study was $135{ }^{\circ} \mathrm{C}$. Another study concerning the encapsulation of tomato oleoresin with zein prepared from corn gluten meal produced by spray drying enabled particle yields of $67.41-76.12 \% .^{42}$ In this case, the highest temperature used was $120^{\circ} \mathrm{C}$. Lower process yields were obtained at lower temperatures once the particles became stickier towards the equipment due to their expected higher water content. Moreover, the spray drier contains dead volume that leads to a large amount of powders stacked along the walls and corners of the equipment that cannot be manually recovered with the brush. The encapsulation efficiency was determined from the tocopherol load that was found to be between $31.40 \%$ and $42.05 \%$. For the same solid concentration, with an increase in temperature, not only a decrease in the antioxidant
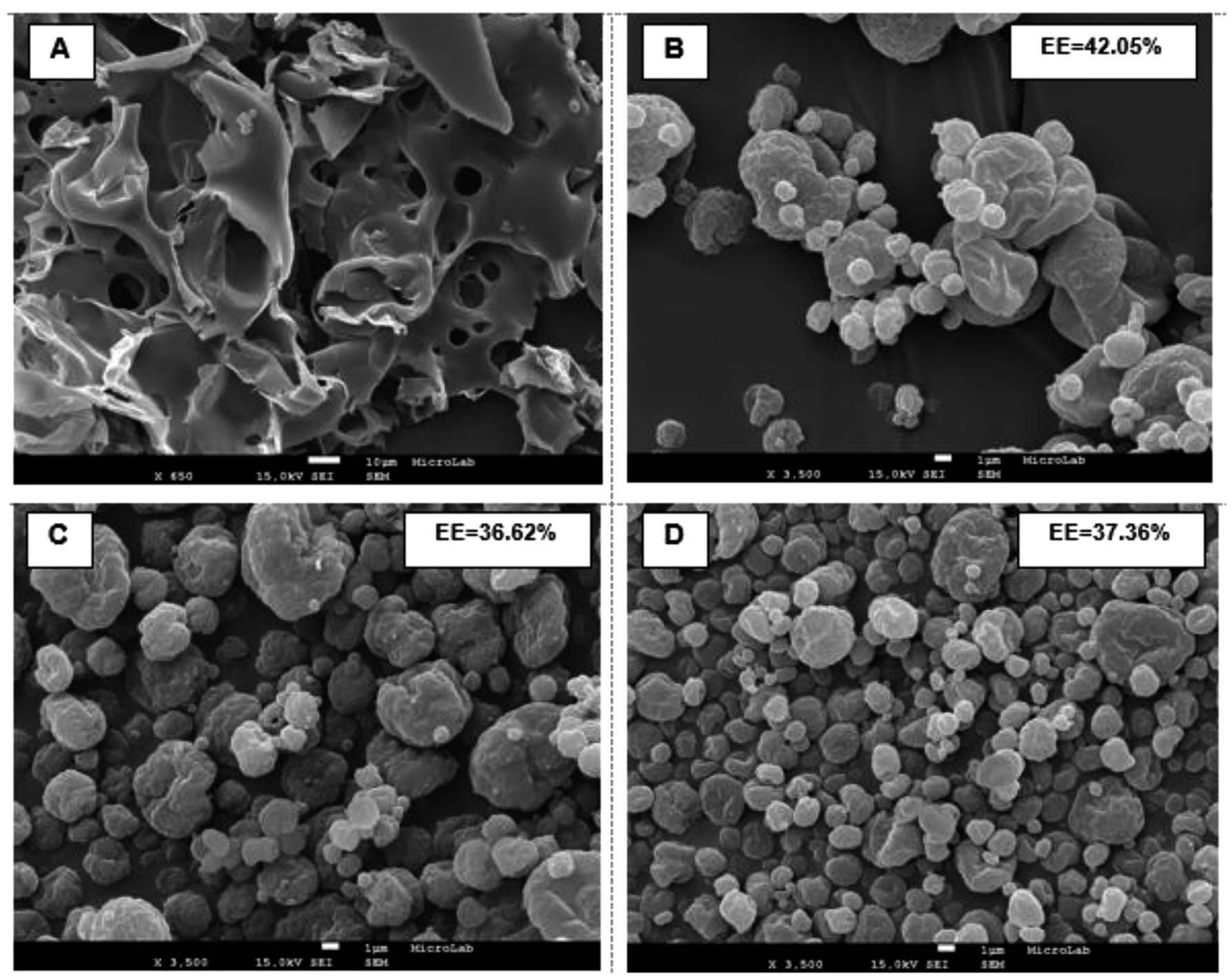

Fig. 2 SEM micrographs: (A) non-spray-dried zein ( $\times 200)$; (B) spray-dried Z:TOC microparticles $\left(110{ }^{\circ} \mathrm{C}, 0.02 \mathrm{~g} \mathrm{~mL}-1\right.$ ); (C) spray-dried Z:TOC microparticles $\left(150^{\circ} \mathrm{C}, 0.02 \mathrm{~g} \mathrm{~mL}^{-1}\right)$; (D) spray-dried Z:TOC microparticles $\left(180^{\circ} \mathrm{C}, 0.02 \mathrm{~g} \mathrm{~mL}^{-1}\right)$. SEM images (B-D) with magnification of $\times 3500$. 
activity was observed but also an increase in the encapsulation load was verified.

SEM micrographs of non-processed zein and spray-dried TOC:Z forms for comparable conditions are presented in Fig. 2.

Non-processed zein had an irregular shape with an internal porous network. This observation is similar to that observed by other authors. ${ }^{\mathbf{4 1 , 4 3}}$

Concerning the spray-dried TOC:Z microparticles, for the same solids concentration, it was possible to visualize an increased deformation when operating at lower temperatures $\left(110^{\circ} \mathrm{C}\right)$ as the solvent diffusion is slower, allowing more time for structures to deform. These results are in agreement with previous studies. ${ }^{\mathbf{4}}$ In the case of microparticles produced with different solids concentration (images not shown), it was possible to visualize a more round shape with increasing solids concentration. Analogous results were obtained by GomezEstaca et al., 2012, during the formation of zein nanoparticles by electrohydrodynamic atomization. ${ }^{45}$

When the concentration of zein was increased to $2.5 \%$, the formation of compact and round particles could be perceived with a smoother surface. The average particle diameter was 1$5 \mu \mathrm{m}\left(110{ }^{\circ} \mathrm{C}, 0.02 \mathrm{~g} \mathrm{~mL}^{-1}\right), 1-5 \mu \mathrm{m}\left(150{ }^{\circ} \mathrm{C}, 0.02 \mathrm{~g} \mathrm{~mL}^{-1}\right)$ and $0.5-5 \mu \mathrm{m}\left(180^{\circ} \mathrm{C}, 0.02 \mathrm{~g} \mathrm{~mL}^{-1}\right)$. Gomez-Estaca et al., 2012, have found an average particle size for zein particles for curcumin encapsulation of about 175-900 nm (ref. 45), and DavidovPardo et al.,2013, have found an average particle size of 4-16 $\mu \mathrm{m}$ for zein microcapsules for encapsulation of a grape seed extract. $^{39}$

\section{Development of CD-Z-TOC complexes}

$\alpha$-Tocopherol:zein particles incorporating $\beta$-cyclodextrin were obtained by spray drying using the optimized process conditions $\left(110^{\circ} \mathrm{C} ; 0.01 \%\right)$. The antioxidant activity of this system was found to be $46.2 \mu \mathrm{mol}$ TEAC per $\mathrm{g}$ particles. SEM images of TOC:CD:Z forms after spray drying are shown in Fig. 3 . From the images captured by SEM for TOC:CD:Z, it was possible to identify the presence of $\beta$-cyclodextrin (CD) with a spherical shape and smooth surface with more or less pronounced concavities. The average particle diameter was found to be around $10 \mu \mathrm{m}$.

\section{FTIR-ATR}

FTIR spectra of $\beta$-cyclodextrin ( $\beta$-CD), zein $(Z)$, spray-dried zein (SD Z), $\alpha$-tocopherol:zein particles (TOC:Z) and $\alpha$-tocopherol:cyclodextrin:zein particles (TOC:CD:Z) are shown in Fig. 4.

All samples presented a strong and broad band peak between 3255 and $3289 \mathrm{~cm}^{-1}$, corresponding to bonded $\mathrm{O}-\mathrm{H}$ stretching. ${ }^{46}$ A broad band due to hydrogen bond appeared normally between 3200 and $3400 \mathrm{~cm}^{-1}$, which is attributed to complex vibrational stretching, associated with free, inter- and intramolecular bound hydroxyl groups. ${ }^{47}$ Nevertheless, bands $3289-3285 \mathrm{~cm}^{-1}$ of all samples except for $\beta$-CD are associated with $\mathrm{N}-\mathrm{H}$ stretching of the amine group, belonging to zein protein. ${ }^{48}$ Band $2927 \mathrm{~cm}^{-1}$ in all samples reveals the presence of $\mathrm{C}-\mathrm{H}$ bonding. ${ }^{49}$

Samples containing zein show a characteristic FTIR spectrum, with bands of amide I at $\sim 1650 \mathrm{~cm}^{-1}$, amide II at $\sim 1530-$ $50 \mathrm{~cm}^{-1}$, and a set of weaker bands that represent amide III vibration modes centered at $\sim 1245 \mathrm{~cm}^{-1}$. ${ }^{50,51}$

For $\beta-\mathrm{CD}$, a band at $1645 \mathrm{~cm}^{-1}$ could be observed corresponding to a $\mathrm{O}-\mathrm{H}$ bending characteristic of this compound. ${ }^{52} \mathrm{~A}$ band at $1525 \mathrm{~cm}^{-1}$ except for $\beta$-CD corresponds to a shift from $\beta$-sheet structure of zein, which absorbs around $1525 \mathrm{~cm}^{-1}$, to $\alpha$-helical structure, which has its amide II maximum at 1545 $\mathrm{cm}^{-1}$. The shift in the amide II peak was shifted to around 1535 $\mathrm{cm}^{-1}$, suggesting the presence of interaction between $\mathrm{CD}$ molecules and zein chains. It is expected that $\beta$-CD sequesters the hydrophobic moieties on the protein surface. ${ }^{53-55} \mathrm{~A}$ band was also observed at the $1447 \mathrm{~cm}^{-1}$ for SD Z, TOC:Z and Z, which is attributed to the vibrations of attached hydrocarbon chains. ${ }^{56}$ Bands at $1156 \mathrm{~cm}^{-1}$ and $1028 \mathrm{~cm}^{-1}$ appearing for pure $\beta-\mathrm{CD}$ and the complexes (TOC:CD:Z) correspond to $\mathrm{C}-\mathrm{O}$ and $\mathrm{CO} / \mathrm{CC}$ stretches, respectively, and are characteristic of this compound. ${ }^{52,57,58}$ According to the literature, $\alpha$-tocopherol presents a characteristic absorption band at $1460 \mathrm{~cm}^{-1}$ for the phenyl skeletal and the overlap of asymmetrical methyl bending and methylene scissoring vibration and at $1377 \mathrm{~cm}^{-1}$ for symmetrical methyl bending. These bands were used to assess the interaction between cyclodextrins and the guest molecule ( $\alpha$-tocopherol) in the solid state. ${ }^{21}$ It is proposed that a tight fitting of $\alpha$-tocopherol within the $\beta$-CD cavity would hinder these molecular vibrations, consequently diminishing the
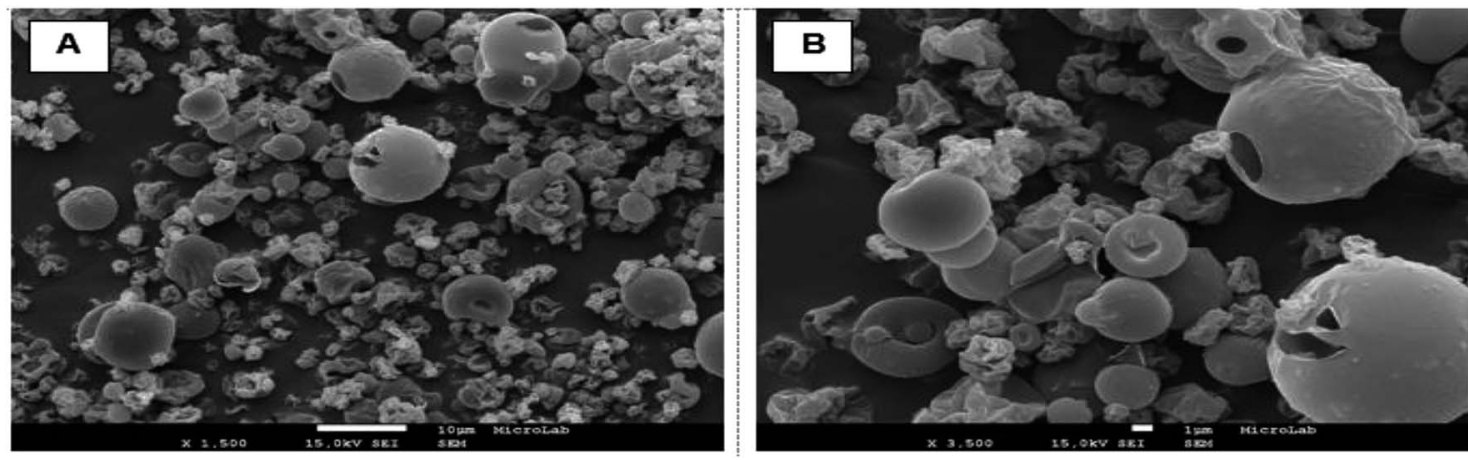

Fig. 3 SEM micrographs: spray-dried TOC:CD:Z with magnification of $\times 1500(A)$ and $\times 3500(B)$. 


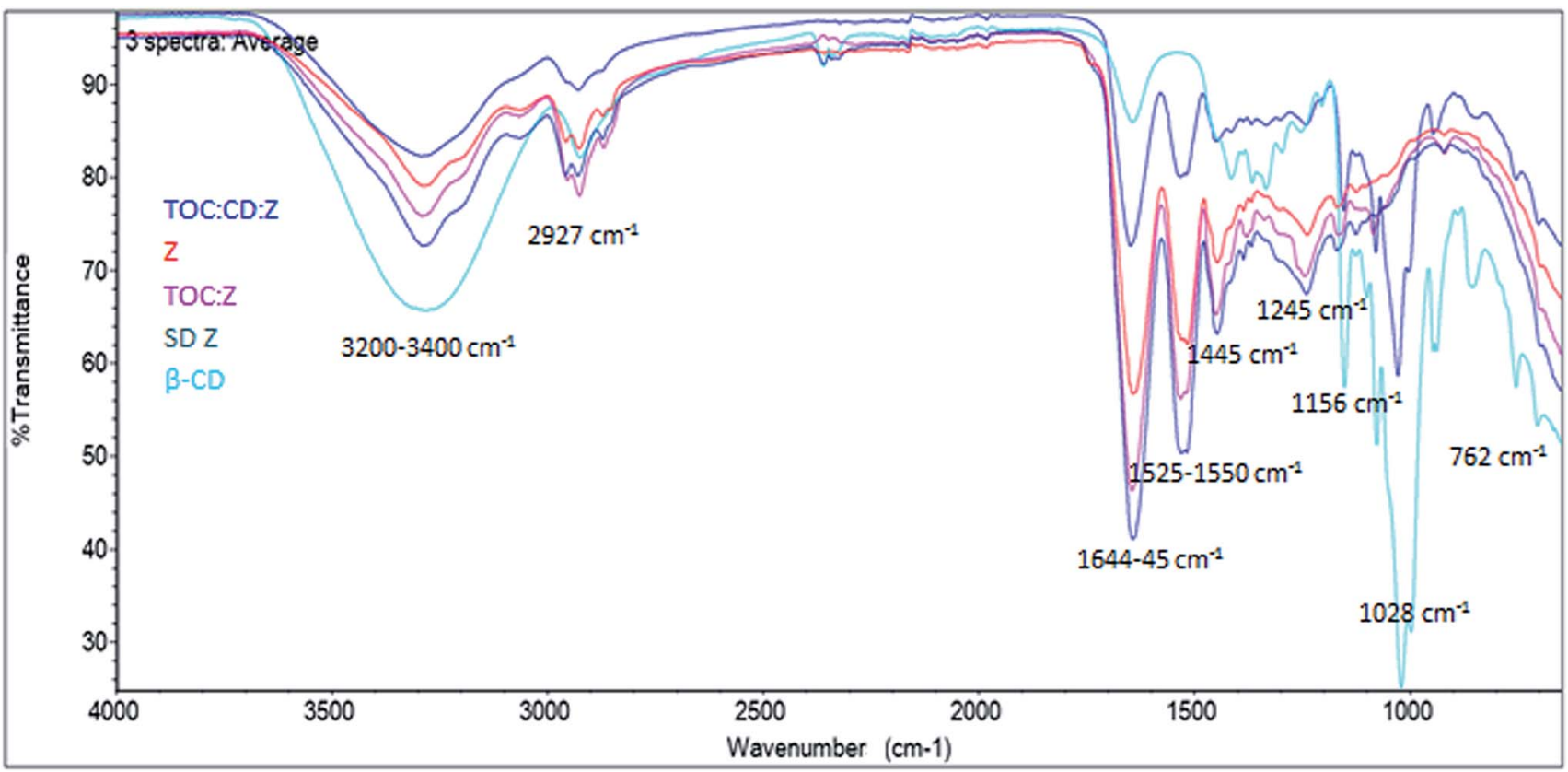

Fig. 4 FTIR spectrum of $\beta$-cyclodextrin ( $\beta$-CD), zein (Z), spray-dried zein (SD Z), $\alpha$-tocopherol:zein particles (TOC:Z) and $\alpha$-tocopherol:cyclodextrin:zein particles (TOC:CD:Z).

intensities of their absorption bands. It is expected that electrostatic interactions occurred between $\alpha$-tocopherol and zein once the bands of amide I and amide II groups of $\alpha$-tocopherol and zein particles were shifted from 1664 and $1550 \mathrm{~cm}^{-1}$ to 1660 and $1547 \mathrm{~cm}^{-1}$, respectively. ${ }^{20}$

The spectrum of the TOC:CD:Z complex appears to be very similar to that of its $\beta$-CD host. These observations are in accordance with what was found by Koontz et al., 2009. ${ }^{21}$ Finally, the band at $762 \mathrm{~cm}^{-1}$ is characteristic of a pyranose ring vibration of $\beta$-CD that is present only for pure $\beta$-CD and the complexes (TOC:CD:Z).

Overall, FTIR spectra confirm the interaction between zein and cyclodextrin and between cyclodextrin and $\alpha$-tocopherol.

\section{DLS}

The particle size distribution of TOC:Z particles obtained by spray drying was analysed by DLS. The average size of particles produced at different drying conditions varied between 1523.3 and $8534.0 \mathrm{~nm}$ (Table 3), being in agreement with SEM images (Fig. 2). The wide range of particle sizes obtained could be also due to some particle aggregation.

\section{Cytotoxicity}

The cytotoxicities of TOC:Z and TOC:CD:Z were assessed using confluent and undifferentiated $\mathrm{Caco} 2$ cells. Because our study was focused on the development of microparticles for food applications, we tested their safety on the gastrointestinal track using an accepted intestinal model, namely Caco2 cell model, which shares some characteristics with crypt enterocytes. ${ }^{59}$ This cell model has been widely implemented to assess the effect of chemicals, food compounds and nanoparticles on the intestinal

\section{Z:TOC- toxicity in Caco2 cell line}

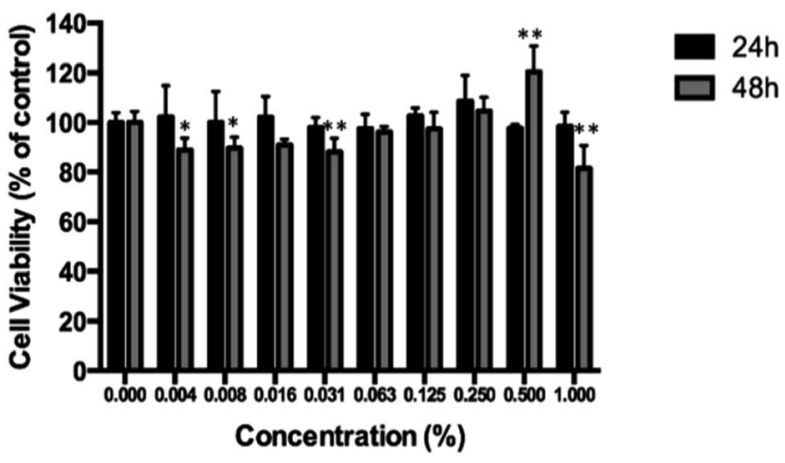

CD:Z:TOC - toxicity in Caco2 cell line

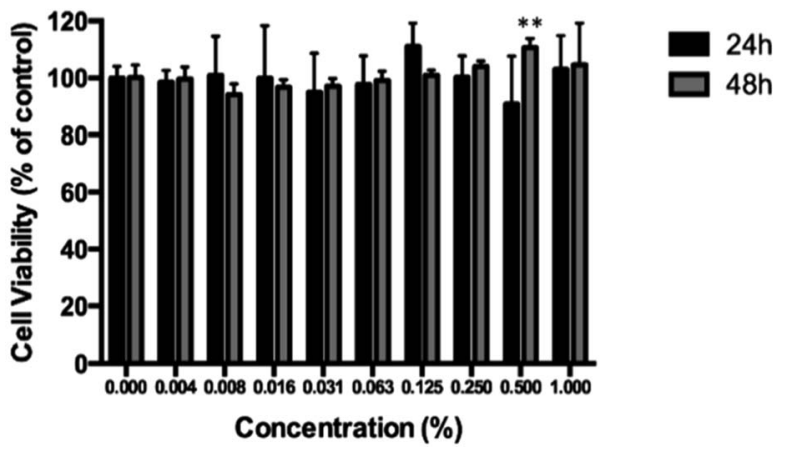

Fig. 5 Percentage of cell viability obtained for $\mathrm{Caco} 2$ cells incubated with increasing concentrations of $\alpha$-tocopherol formulations during 24 and 48 hours. Results are means of 2 independent experiments performed in triplicate \pm SD. For both assays, a $p<0.05$ was considered as statistically significant; $* p<0.05$ and $* * p<0.01$ are relative to respective control. 
Table 5 Colour properties of freshly prepared strawberry juice without (control sample) and with free TOC (+TOC), TOC:Z particles (+TOC:Z) and TOC:CD:Z particles (+TOC:CD:Z)

\begin{tabular}{|c|c|c|c|c|c|c|c|}
\hline & $t$ & $L^{*}$ & $a^{*}$ & $b^{*}$ & $C^{*}$ & $h^{\circ}$ & $\Delta E^{*}$ \\
\hline \multirow[t]{2}{*}{ Control (juice) } & 0 & $30.83 \pm 0.12$ & $25.86 \pm 0.31$ & $12.76 \pm 0.21$ & 28.84 & 26.26 & 0.00 \\
\hline & 10 & $30.80 \pm 0.06$ & $18.58 \pm 0.02$ & $7.86 \pm 0.01$ & 20.18 & 22.93 & 8.77 \\
\hline \multirow[t]{2}{*}{ +TOC } & 0 & $29.98 \pm 0.20$ & $23.90 \pm 0.04$ & $10.95 \pm 0.08$ & 26.29 & 24.62 & 0.00 \\
\hline & 10 & $31.40 \pm 0.01$ & $19.31 \pm 0.05$ & $8.59 \pm 0.02$ & 21.14 & 23.98 & 5.35 \\
\hline \multirow[t]{2}{*}{ +TOC:Z } & 0 & $32.09 \pm 0.29$ & $24.24 \pm 0.40$ & $10.81 \pm 0.30$ & 26.53 & 24.04 & 0.00 \\
\hline & 10 & $31.64 \pm 0.04$ & $18.66 \pm 0.08$ & $8.03 \pm 0.04$ & 20.31 & 23.28 & 6.25 \\
\hline \multirow[t]{2}{*}{ +TOC:CD:Z } & 0 & $31.05 \pm 0.16$ & $23.27 \pm 0.47$ & $11.38 \pm 0.06$ & 25.90 & 26.06 & 0.00 \\
\hline & 10 & $32.13 \pm 0.05$ & $16.82 \pm 0.51$ & $8.38 \pm 0.03$ & 18.79 & 26.48 & 6.16 \\
\hline
\end{tabular}

function as described by several authors. ${ }^{32,33,59,60}$ As shown in Fig. 5, cell viability obtained after 24 hours of incubation with different concentrations of TOC formulations did not significantly decrease $(p>0.05)$ relative to the control group (cells with RPMI medium). However, when Caco2 cells were incubated for $48 \mathrm{~h}$ with Z:TOC samples, a slight decrease (up to $15 \%$ reduction) was observed. Importantly, the sample CD:Z:TOC did not show cytotoxic effect at $48 \mathrm{~h}$ of incubation, indicating that the addition of $\beta$-cyclodextrin to the system decreased the cytotoxic effects of Z:TOC, as previously suggested by other authors..$^{61,62}$ As expected, free TOC did not present cytotoxic effect in this cell line (data not shown).

\section{Shelf-life stability}

To assess the commercial applicability for the obtained TOC:Z and TOC:CD:Z forms, their performance in freshly prepared strawberry juice was evaluated. The quantity of TOC:Z forms added to the juice was $1 \%$, whereas for TOC:CD:Z forms, a lower amount was incorporated $(0.59 \%)$, taking into account the maximum amount of $\beta$-CD allowed in beverages. ${ }^{63}$ The obtained results concerning the colour properties are present in Table 5. The CIELab system was used to define the colour properties, and $L^{*}, a^{*}, b^{*}, C^{*}, h^{\circ}$ and $\Delta E^{*}$ were calculated. Lightness of freshly prepared juice without (control sample) and with addition of free TOC (+TOC), TOC:Z forms (+TOC:Z) and TOC:CD:Z forms (+TOC:CD:Z) did not change much throughout the accelerated aging time. However, great changes were verified for $a^{*}$ (green-red) and $b^{*}$ values (blueness-yellowness) for all samples compared to their respective control samples $(t=0)$. Chroma, which expresses the brilliance or purity of a colour, decreased and the hue angle, which indicated the tonality, also decreased with aging. The total colour difference value $\left(\Delta E^{*}\right)$ is a measurement of the extent to which the colour of the other samples was similar to the control samples $(t=0)$.

It may be considered that more than 5 units of difference indicates that the human eye is capable of distinguishing between these colours. An overall color difference of $0-1.5$ can be considered small, which indicates that the sample is almost identical to the original by visual observation.

When the $\Delta E^{*}$ value is located within the range of $1.5-5$, the colour difference can be distinguished, and this difference becomes evident when the $\Delta E^{*}$ value is greater than $5 .{ }^{64}$

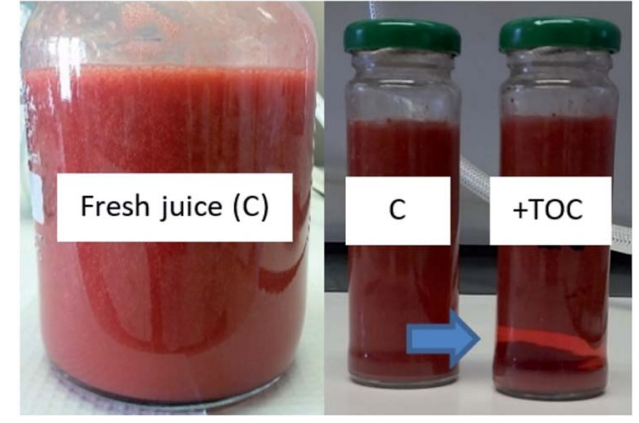

Fig. 6 Phase separation upon addition of TOC (+TOC) into the strawberry juice compared to the juice without addition of TOC (C), after accelerating aging (10 days).

It is important to mention that free TOC leads to phase separation after accelerated aging (Fig. 6). This observation was expected because vitamin $\mathrm{E}$ is not soluble in aqueous systems, and therefore, it is important to find solutions so it can be used in beverages. Upon its addition in beverages, it is common to observe vitamin E droplets gradually rising to the surface of a beverage bottle within days and forming a ring around the bottle. $^{8}$

Concerning TOC:Z:CD forms, the hue angle, which indicated the tonality, also did not decrease with accelerated aging. Even though TOC:Z:CD particles presented antioxidant activity lower than that of TOC:Z particles, their performance seemed to be better for protection against degradation. This can probably be explained by the capacity of $\beta$-cyclodextrin to suppress anthocyanin degradation ${ }^{65}$ due to the formation of inclusion complexes (Mourtzinos et al., 2008).

\section{Conclusions}

This study demonstrated that the use of TOC:Z and TOC:CD:Z forms prepared by spray drying is a promising approach to prolong the shelf-life of beverages due to its antioxidant properties and good dispersibility and solubility. Under an inlet gas temperature of $110^{\circ} \mathrm{C}$ and solids concentration of $0.01 \mathrm{~g} \mathrm{~L}^{-1}$, the TOC:Z and TOC:CD:Z forms presented antioxidant activity (ORAC) of 106.2 and $46.2 \mu \mathrm{mol}$ TEACper g particles, respectively. High correlation between experimental data and theoretical values predicted by the model were obtained (92\%). The 
average particle size was shown to be between 1 and $9 \mu \mathrm{m}$. After accelerated aging studies, TOC:Z and TOC:CD:Z forms enabled less colour losses compared to the juice without the addition of the forms. Future studies need to be performed in order to optimize the development of TOC:CD:Z forms and further investigate the insights generated in this study. The information produced in this study will be useful for designing delivery systems containing active lipophilic components for applications in foods and beverages for improved quality.

\section{Acknowledgements}

This study acknowledges Fundação para a Ciência e Tecnologia (FCT) through the doctoral fellowship (SFRH/BDE/51856/2012), R\&D units iNOVA4Health - UID/Multi/04462/2013 and GreenIT - UID/Multi/04551/2013, programs financially supported by FCT/Ministério da Educação e Ciência, through national funds and co-funded by FEDER under the PT2020 Partnership Agreement.

\section{References}

1 L. Chen, G. E. Remondetto and M. Subirade, Trends Food Sci. Technol., 2006, 17, 272-283.

2 Z.-L. Wan, J. Guo and X.-Q. Yang, Food Funct., 2015, 6, 28762889.

3 J. Lee, L. Ye, W. O. Landen Jr and R. R. Eitenmiller, J. Food Compos. Anal., 2000, 13, 45-57.

4 R. S. London, G. S. Sundaram, L. Murphy and P. J. Goldstein, J. Am. Coll. Nutr., 1983, 2, 115-122.

5 S. Marubayashi, K. Dohi, K. Ochi and T. Kawasaki, Surgery, 2016, 99, 184-192.

6 M. Kunisaki, S.-E. Bursell, F. Umeda, H. Nawata and G. L. King, BioFactors, 1998, 7, 55-67.

7 F. Andıran, A. Ayhan, F. C. Tanyel, O. Abbasoğlu and İ. Sayek, J. Surg. Res., 2000, 89, 184-188.

8 K. Kailasapathy, in Advances in Food Biotechnology, ed. Ravishankar Rai V, John Wiley \& Sons Ltd, Chichester, UK, 2015, pp. 311-334.

9 H. Chen and Q. Zhong, Food Hydrocolloids, 2015, 43, 593602.

10 S.-H. Yoo, Y.-B. Song, P.-S. Chang and H. G. Lee, Int. J. Biol. Macromol., 2006, 38, 25-30.

11 M. L. Zambrano-Zaragoza, E. Mercado-Silva, A. Del Real L, E. Gutiérrez-Cortez, M. A. Cornejo-Villegas and D. QuintanarGuerrero, Innovative Food Sci. Emerging Technol., 2014, 22, 188-196.

12 H. Chen and Q. Zhong, Food Hydrocolloids, 2014, 35, 358366.

13 Y. Luo and Q. Wang, J. Appl. Polym. Sci., 2014, 131, 1-12.

14 C. G. Drosou, M. K. Krokida and C. G. Biliaderis, Drying Technol., 2017, 35(2), 139-162.

15 G. W. Selling, A. Biswas, A. Patel, D. J. Walls, C. Dunlap and Y. Wei, Macromol. Chem. Phys., 2007, 208, 1002-1010.

16 A. Patel, Y. Hu, J. K. Tiwari and K. P. Velikov, Soft Matter, 2010, 6, 6192-6199.
17 Y. Luo, Z. Teng and Q. Wang, J. Agric. Food Chem., 2012, 60, 836-843.

18 D. Hu, C. Lin, L. Liu, S. Li and Y. Zhao, J. Food Eng., 2012, 109, 545-552.

19 A. R. Patel, P. C. M. Heussen, J. Hazekamp, E. Drost and K. P. Velikov, Food Chem., 2012, 133, 423-429.

20 Y. Luo, B. Zhang, M. Whent, L. Yu and Q. Wang, Colloids Surf., B, 2011, 85, 145-152.

21 J. L. Koontz, J. E. Marcy, S. F. O'Keefe and S. E. Duncan, J. Agric. Food Chem., 2009, 57, 1162-1171.

22 A. R. Patel and K. P. Velikov, Curr. Opin. Colloid Interface Sci., 2014, 19, 450-458.

23 A. K. Chatjigakis, C. Donze, A. W. Coleman and P. Cardot, Anal. Chem., 1992, 64, 1632-1634.

24 T. Lundstedt, E. Seifert, L. Abramo, B. Thelin, Å. Nyström, J. Pettersen and R. Bergman, Chemom. Intell. Lab. Syst., 1998, 42, 3-40.

25 M. C. Regier, J. D. Taylor, T. Borcyk, Y. Yang and A. K. Pannier, J. Nanobiotechnol., 2012, 10, 44.

26 D. Huang, B. Ou, M. Hampsch-Woodill, J. A. Flanagan and R. L. Prior, J. Agric. Food Chem., 2002, 50, 4437-4444.

27 R. Feliciano, M. Bravo, M. Pires, A. Serra, C. Duarte, L. Boas and M. Bronze, Food Anal. Methods, 2009, 2, 149-161.

28 B. W. Bolling, Y.-Y. Chen, A. G. Kamil and C.-Y. O. Chen, J. Food Sci., 2012, 77, H69-H75.

29 M. C. Gacula Jr, Statistical methods in food and consumer research, Elsevier, 2013.

30 P. D. Haaland, Experimental design in biotechnology, CRC press, 1989, vol. 105.

31 Y. Sambuy, I. De Angelis, G. Ranaldi, M. L. Scarino, A. Stammati and F. Zucco, Cell Biol. Toxicol., 2005, 21, 1-26.

32 G. Manda, A. M. Mocanu, E. D. Marin and I. Taranu, Toxins, 2015, 7, 593-603.

33 G. Cano-Sancho, C. A. González-Arias, A. J. Ramos, V. Sanchis and M. L. Fernández-Cruz, Toxicol. In Vitro, 2015, 29, 1639-1646.

34 A. T. Serra, A. A. Matias, R. F. M. Frade, R. O. Duarte, R. P. Feliciano, M. R. Bronze, M. E. Figueira, A. de Carvalho and C. M. M. Duarte, J. Funct. Foods, 2010, 2, 46-53. 35 R. Cassano, T. Ferrarelli, A. G. Schätzlein, I. F. Uchegbu and S. Trombino, Eur. J. Pharm. Biopharm., 2013, 84, 540-548.

36 V. Rocha, C. Marques, J. L. Figueiredo, A. R. Gaio, P. C. Costa, J. M. S. Lobo and I. F. Almeida, Food Chem. Toxicol., 2017, 103, 214-222.

37 T. Mosmann and J. Immunol, Methods, 1983, 65, 55-63.

38 International Organization for Standardization, Colorimetry - Part 4: CIE $1976 L^{*} a^{*} b^{*}$ Colour Space, 2008.

39 G. Davidov-Pardo, I. Arozarena and M. R. Marín-Arroyo, Food Bioprocess Technol., 2013, 6, 941-951.

40 R. Murugesan and V. Orsat, Food Bioprocess Technol., 2012, 5, 3-14.

41 S. Quispe-Condori, M. D. a. Saldaña and F. Temelli, LWTFood Sci. Technol., 2011, 44, 1880-1887.

42 F. Xue, C. Li, Y. Liu, X. Zhu, S. Pan and L. Wang, J. Food Eng., 2013, 119, 439-445.

43 Q. Zhong, M. Jin, P. M. Davidson and S. Zivanovic, Food Chem., 2009, 115, 697-700. 
44 F. Gandía-Herrero, M. Jiménez-Atiénzar, J. Cabanes, F. García-Carmona and J. Escribano, J. Agric. Food Chem., 2010, 58, 10646-10652.

45 J. Gomez-Estaca, M. P. Balaguer, R. Gavara and P. Hernandez-Munoz, Food Hydrocolloids, 2012, 28, 82-91.

46 L. Wang, D. A. Schiraldi and M. Sánchez-Soto, Ind. Eng. Chem. Res., 2014, 53, 7680-7687.

47 V. Paşcalău, V. Popescu, G. L. Popescu, M. C. Dudescu, G. Borodi, A. Dinescu, I. Perhaiţa and M. Paul, J. Alloys Compd., 2012, 536, S418-S423.

48 A. A. Shamsuri, D. D. Abdullah and R. Daik, Cellul. Chem. Technol., 2012, 46, 45-52.

49 W. Liu, X. Yan, J. Chen, Y. Feng and Q. Xue, Nanoscale, 2013, 5, 6053-6062.

50 K. J. Payne and A. Veis, Biopolymers, 1988, 27, 1749-1760.

51 D. J. Sessa and K. K. Woods, J. Am. Oil Chem. Soc., 2011, 88, 1037-1043.

52 S. Songkro, N. Hayook, J. Jaisawang, D. Maneenuan, T. Chuchome and N. Kaewnopparat, J. Inclusion Phenom. Macrocyclic Chem., 2012, 72, 339-355.

53 F. L. Aachmann, D. E. Otzen, K. L. Larsen and R. Wimmer, Protein Eng., Des. Sel., 2003, 16, 905-912.

54 F. Kayaci and T. Uyar, Carbohydr. Polym., 2012, 90, 558-568. 55 T. Uyar, A. Balan, L. Toppare and F. Besenbacher, Polymer, 2009, 50, 475-480.
56 S. K. Pankaj, C. Bueno-Ferrer, N. N. Misra, L. O'Neill, A. Jiménez, P. Bourke and P. J. Cullen, Innovative Food Sci. Emerging Technol., 2014, 21, 107-113.

57 A. Fernandez, S. Torres-Giner and J. M. Lagaron, Food Hydrocolloids, 2009, 23, 1427-1432.

58 C. Yao, X. Li, T. Song, Y. Li and Y. Pu, Polym. Int., 2009, 58, 396-402.

59 Y. Sambruy, S. Ferruzza, G. Ranaldi and I. De Angelis, in Cell Culture Methods for In Vitro Toxicology, Springer, 2001, pp. 97-113.

60 J. Martins, Ó. Ramos, A. Pinheiro, A. Bourbon, H. Silva, M. Rivera, M. Cerqueira, L. Pastrana, F. X. Malcata, Á. González-Fernández and A. Vicente, Food Eng. Rev., 2015, 1-23.

61 F. Gómez-Galván, L. Pérez-Álvarez, J. Matas, A. ÁlvarezBautista, J. Poejo, C. M. Duarte, L. Ruiz-Rubio, J. L. VilaVilela and L. M. León, Carbohydr. Polym., 2016, 142, 149-157. 62 P. Tang, S. Li, L. Wang, H. Yang, J. Yan and H. Li, Carbohydr. Polym., 2015, 131, 297-305.

63 W. B. Corp, FDA, JECFA SCF.

64 J. M. Obon, M. R. Castellar, M. Alacid and J. A. FernandezLopez, J. Food Eng., 2009, 90, 471-479.

65 Y. Watanabe, K. Yoshimoto, Y. Okada and M. Nomura, LWTFood Sci. Technol., 2011, 44, 891-895. 